\title{
CIÊNCIAS HUMANAS \\ Jogos Escolares de Petrolina: apontamentos históricos (década de 1970)
}

Petrolina School Games: historical notes (1970s)

Luciano Juchem'; Marines Matter de Souza²; Tuany Defaveri Begossi²; Carlos Adelar Abaide Balbinotti ${ }^{2}$

\section{RESUMO}

Os Jogos Escolares de Petrolina (JEP) é uma competição esportiva escolar realizada entre alunos de escolas públicas e privadas da cidade de Petrolina, em Pernambuco, que existe há mais de 45 anos. Dada sua importância junto à comunidade, o presente estudo teve por objetivo investigar como sucederam as primeiras edições dos JEP ocorridas nos primeiros anos da década de 1970. Para tal, foram analisadas fontes impressas e fontes orais, sendo essas últimas obtidas por meio da gravação de entrevistas com professores que participaram da criação dos JEP. Além disso, foi realizada uma revisão bibliográfica sobre a temática dos jogos escolares. A análise dos dados revelou que a criação dos JEP foi uma incumbência dada pelo Departamento Regional de Educação (DERE), a três professores de Educação Física, que ocupavam também cargos de policiais militares. As primeiras edições da competição escolar tinham semelhanças com competições que privilegiavam o esporte olímpico de alto rendimento. No que concerne à Educação Física, ressaltamos como reflexo do movimento advindo com a ditadura militar, a inserção e o estímulo da prática esportiva nas aulas desta disciplina, além da realização de competições escolares.

Palavras-chave: Jogos Escolares; Competição esportiva; Escola.

\section{ABSTRACT}

The Petrolina School Games (JEP) is a school sports competition held between students of public and private schools in the city of Petrolina, in Pernambuco, which has existed for more than 45 years. Given its importance to the community, the present study aimed to investigate how the first editions of the JEP occurred in the early 1970s. For this, we analyzed printed sources and oral sources which were obtained through the recording of interviews with teachers who participated in the creation of JEPS. In addition, a bibliographic review was carried out on the theme of school games. The analysis of the data revealed that the creation of the JEP was an errand given by the Regional Department of Education (DERE), to three Physical Education teachers, who also held positions of military police. The first editions of the school competition had similarities to competitions that favored the high-performance Olympic sport. With regard to Physical Education, we highlight the reflex of the movement with the military dictatorship, the insertion and the stimulation of the sports practice in the classes of this discipline, besides the accomplishment of school competitions.

Keywords: School Games; Sports competition; School.

\footnotetext{
1 UNIVASF - Universidade Federal do Vale do São Francisco, Petrolina/PE - Brasil.

2 UFRGS - Universidade Federal do Rio Grande do Sul, Porto Alegre/RS - Brasil.
} 


\section{INTRODUÇÃO}

Os Jogos escolares de Petrolina (JEP) são caracterizados como sendo uma competição esportiva, que congrega crianças e adolescentes de escolas públicas e privadas de Petrolina, município localizado no estado de Pernambuco. Dentre as especificidades do referido evento esportivo está o fato de este estar sendo realizado anualmente desde 1970. Esta característica, por sua vez, demarca sua representatividade perante o contexto no qual é realizado, demonstrando sua consolidação no calendário escolar. Ressaltamos ainda que no corrente ano ocorre a 48a edição dos JEP.

Diante do exposto, o presente estudo tem por objetivo investigar como se sucederam as primeiras edições dos JEP no princípio da década de 1970. Para tanto, compuseram nosso corpus de pesquisa documentos impressos e orais, os quais foram interpretados por meio da análise de conteúdo temática (FLICK, 2009; GIBBS, 2009). Destacamos que os referidos materiais foram obtidos por meio da realização de entrevistas com professores que participaram da criação dos JEP em Petrolina. Para além desta documentação, realizamos também uma revisão bibliográfica sobre a temática dos jogos escolares.

De tal modo, os resultados do estudo são apresentados por meio da "triangulação" de distintas informações (GOLDENBERG, 2015, p. 69). Segundo a autora (2015, p.69), a "triangulação" trata-se de uma "metáfora tomada emprestada da estratégia militar, que se utiliza de múltiplos pontos de referência para localizar a posição exata de um objeto". Assim, tendo por intuito abranger a máxima amplitude na descrição, explicação e compreensão dos pontos suscitados por meio do contato com os documentos, a investigação foi permeada por interpretações e releituras, construídas a partir de representações que chegaram até nós, através dos materiais de pesquisa acessados (CHARTIER, 1994).

Nesta direção, o presente estudo está ancorado nos pressupostos teórico-metodológicos da História Cultural (BURKE, 2008), sendo compreendido como uma leitura dos acontecimentos históricos mencionados, sem a pretensão, portanto, de construir uma verdade única e inquestionável (CHARTIER, 2009). Para Pesavento (2004), as "representações" podem ser vistas como uma reapresentação de algo que se encontra ausente no tempo e no espaço. Desta forma, o pesquisador fará uma tentativa de leitura de outro tempo, o qual só se torna possível de ser acessado através de registros e sinais que chegam até o presente (PESAVENTO, 2004).

Nesta perspectiva, apresentamos nos tópicos que seguem os resultados obtidos por meio do cotejamento de distintas informações, sendo a escrita orientada pelos pressupostos teóricometodológicos da História Cultural (CHARTIER, 1994; PESAVENTO, 2004; BURKE, 2008; CHARTIER, 2009). No que diz respeito aos procedimentos éticos, este estudo fez parte de um projeto guardachuva, aprovado pelo Comitê de Ética em pesquisa, da Universidade Federal do Rio Grande do Sul (UFRGS), sob o número do protocolo 271526.

\section{O PROCESSO DE CONFORMAÇÃO DOS JEP}

De acordo com Reverdito et al, (2008), os jogos escolares são considerados um evento esportivo, organizado e promovido pelas instituições de ensino, onde ocorrem competições entre turmas e séries. Os Jogos escolares de Petrolina (JEP), objeto de análise do presente estudo, podem ser considerados uma manifestação esportiva já consolidada neste âmbito. Apesar disso, o registro com 
relação ao seu início possui controvérsias, sobretudo em razão de não ter sido documentado de modo oficial, as tratativas para sua realização. Por esta razão, as informações acerca da organização inicial deste evento podem ser acessadas, especialmente, através da oralidade, por meio de testemunhos narrados por sujeitos que vivenciaram este processo.

No presente estudo, evidenciamos o relato do professor Otacílio de Souza Lima que, na época em que foram evidenciadas as iniciativas para a organização dos JEP, era estudante da Escola Marechal Antônio Alves Filho (EMAAF). Naquele contexto dos anos de 1970, o professor Otacílio, além de ocupar a posição de estudante, participou auxiliando na organização das primeiras edições do evento. Segundo relatado em seu depoimento, no período em que foram engendrados os passos iniciais dos JEP, não foi realizado sequer um registro impresso a respeito do que ele denominou de "primeiros jogos oficiais" (LIMA, 2015, p. 1).

Embora mencione em seu depoimento a falta de uma documentação que confirme as iniciativas frente ao que veio a se tornar os JEP, o professor Otacílio relata o empenho do professor "Frota" na organização de uma competição de Atletismo (corrida de, aproximadamente, 100 metros), no Estádio Municipal de Petrolina, disputada entre as escolas da cidade, no ano de 1969 (LIMA, 2015, p. 1). 0 percurso, conforme rememorado em sua fala, compreendia uma lateral a outra do Estádio Municipal e foi vencida por Gilberto Machado Lima (LIMA, 2015). Ao que consta na fala narrada pelo professor Otacílio (2015), esta foi a primeira competição entre escolas, realizada em Petrolina.

De outro modo, a versão narrada pela Secretaria de Esportes de Petrolina toma o ano de 1970, como marco da realização da primeira edição dos JEP. Este dado, por sua vez, foi apontado durante um discurso proferido na cerimônia de abertura da quadragésima edição do evento, no ano de 2010. Na ocasião, foram homenageados gestores do Centro Regional de Esportes e Lazer, além de técnicos e atletas que se destacaram ao longo da trajetória do referido evento esportivo (JUCHEM, 2015).

Para além das diferentes versões aludidas, podemos mencionar a localização de registros fotográficos de troféus do Colégio Dom Bosco, Nossa Senhora Auxiliadora e da Escola Marechal Antônio Alves Filho (EMAAF). Tais indícios nos conduzem no traçado de (novas) evidências sobre o ano em que os JEP passaram a ocorrer de modo oficial. Assim, conforme consta no registro dos referidos objetos, os $1^{\circ} \mathrm{s}$ Jogos estudantis de Petrolina foram levados a feito no ano de 1971.

Neste caminho, se por um lado a rememoração do professor Otacílio nos conduz a demarcar o início dos JEP no ano de 1969, por outro, os rastros do passado, materializados por meio do discurso proferido por um representante da Secretaria de Esportes de Petrolina e através das fotografias localizadas, nos remetem a fixar também os anos de 1970 e 1971 como marcos significativos do referido evento esportivo. Talvez, estas distintas datas (1969, 1970 e 1971) confluam justamente no processo de construção dos JEP, o qual provavelmente tenha iniciado ainda no ano de 1969, com a disputa de apenas uma modalidade e que, aos poucos, foi agregando representações que denotam características organizacionais maiores, tais como a entrega de troféus às escolas participantes.

Como sujeitos pioneiros deste processo de edificação dos JEP, figuram os professores Bernardino Pires Teixeira, José Lima Granja e José Pereira Bispo, sendo os professores Bernardino e José Lima Granja colaboradores diretos da presente investigação, por meio de seus depoimentos orais. Na época em que as primeiras articulações para criação do evento foram sendo engendradas (1970), tais professores, além de se envolverem no processo de concepção e organização, ocupavam o cargo de 
policiais militares e, também atuavam como professores de Educação Física, nas escolas de Petrolina. Ressaltamos que os mencionados professores não possuíam uma formação superior específica na área. Contudo, naquele período, conforme constava na Constituição Federal, era permitido que os militares exercessem função docente dentro de instituições de ensino, nas horas em que não estavam em serviço no interior das corporações. De tal modo, ministravam aulas de Educação Física devido às suas experiências com a prática esportiva e com atividades físicas, que haviam sido adquiridas na carreira militar. É válido mencionarmos ainda, que tais profissionais assumiam esta função docente, visto a ausência de professores de Educação Física diplomados, para atuação com esta disciplina nas escolas ${ }^{3}$.

O envolvimento com a Educação Física escolar de Petrolina e, especialmente, com a organização inicial dos JEP nos anos de 1970 foi remorada em depoimento pelo professor Bernardino Pires Teixeira (TEIXEIRA, 2015). Em sua narrativa, mencionou que juntamente com o professor José Lima Granja e com o professor José Pereira Bispo, viajou a Recife para participar do Curso Básico de Formação em Educação Física, com duração de um mês e composto por aulas nos três turnos, no ano de $1970^{4}$. Tal curso, por sua vez, autorizava o exercício do trabalho com a Educação Física ${ }^{5}$. É válido mencionarmos ainda, que na década de 1970, o governo militar investiu de certa forma, na Educação Física, em função das diretrizes pautadas no nacionalismo, na integração entre os estados e na segurança nacional visando, dentre outros aspectos, a formação de um exército composto por integrantes saudáveis e fortes (BRASIL, 1998).

Após a conclusão do Curso, os professores mencionados acima receberam a incumbência da Divisão Regional de Educação (DRE), atual Gerência Regional de Educação (GERE), para realizarem os primeiros Jogos Escolares, na cidade de Petrolina. Na época, a intenção da DRE era interiorizar os Jogos Escolares de Pernambuco, competição que havia sido estruturada durante o final da década de 1950 (JUCHEM, 2015). Perante a missão recebida, os professores realizaram uma reunião visando à organização dos primeiros JEP, nas dependências do colégio Nossa Senhora Auxiliadora - instituição particular de ensino, situada no Bairro Centro, em Petrolina - que se distinguia das demais escolas, tanto das públicas como das privadas, pelas ótimas instalações físicas. Segundo mencionado no depoimento do professor Otacílio, participaram da reunião os professores do próprio colégio Nossa Senhora Auxiliadora, além de docentes do colégio Dom Bosco, da EMAAF, do Colégio de Petrolina, do Colégio Eduardo Coelho e o representante da prefeitura de Petrolina, o professor Samuel Freitas (LIMA, 2015).

O encontro resultou na iniciativa de promover a primeira edição dos JEP, mesmo não havendo condições físicas e financeiras adequadas para tal. Sem apoio governamental e com carências no que se refere à infraestrutura, os primeiros JEP foram organizados contando, sobretudo, com o apoio e colaboração dos professores de Educação Física, alunos e das direções das escolas participantes. De acordo com o depoimento do professor José Lima Granja, em muitos locais foi necessário que os professores e organizadores improvisassem melhores condições para que os jogos pudessem ocorrer,

\footnotetext{
${ }_{3}^{3}$ Cabe destacar que o primeiro curso de Licenciatura em Educação Física na região começou a ser oferecido em 01/03/1973, pela Universidade Federal de Pernambuco (UFPe), situada na cidade de Recife (LYRA, 2013).

${ }^{4}$ Estudos apontam a realização de cursos intensivos de Educação Física, no estado do Rio Grande do Sul, realizados durante o período de férias escolares, no ano de 1929 (PICCOLI, 1994; LYRA, MAZO, 2011; BEGOSSI, 2017). Além deste, há indícios da ocorrência de cursos de Educação Física destinados aos(as) professores(as) estaduais no estado do Espírito Santo (1931) e Piauí (1939) os quais, também, eram realizados durante o período de recesso escolar (BEGOSSI, 2017).

${ }^{5}$ Vale mencionar que, na época, este era o modelo de formação circulante no Brasil. Para mais informações sobre o assunto recomenda-se o texto de LYRA (2013).
} 
uma vez que, cada docente organizava a modalidade esportiva em disputa, dentro da sua escola. Ressalta ainda, que diversos alunos participaram dos Jogos como atletas e, paralelamente a essa condição, colaboraram com a organização. Dentre esses alunos, o professor Granja destacou a cooperação de Otacílio de Souza Nunes e José Pereira Bispo, os quais, posteriormente, vieram a se tornar professores de Educação Física (GRANJA, 2015).

O regulamento que regia a competição dos primeiros JEP foi trazido do Curso de formação, do qual os professores haviam participado em Recife. Devido à falta de estrutura, bem como da ausência de árbitros na cidade de Petrolina, os próprios professores das escolas assumiram, naquele momento, a função de árbitros. Estes, por sua vez, eram auxiliados por seus próprios alunos. Desta forma, é interessante pontuarmos que os professores atuaram nesse cenário inicial dos JEP em uma dupla função, ou seja, ao mesmo tempo em que eram treinadores de suas equipes, também desempenhavam o papel de árbitros na competição escolar. Acerca dos espaços utilizados para realização da primeira edição da competição, o professor Otacílio menciona em seu depoimento, que o local utilizado para as disputas da modalidade de futsal, pertencia ao Colégio Dom Bosco (LIMA, 2015). De acordo com o professor Granja, na época, esta era a escola com a melhor estrutura para a competição escolar (GRANJA, 2015). Os jogos de voleibol, de outro modo, foram realizados no colégio Nossa Senhora Auxiliadora e as competições de atletismo, na EMAAF (JUCHEM, 2015).

Diante do exposto, é possível evidenciarmos que, apesar de não haver registros impressos dos primeiros JEP notamos, por meio dos depoimentos dos professores entrevistados, tidos como pioneiros deste cenário, que a organização dos Jogos estudantis percorreu um caminho de transformações até a sua efetivação. Um ponto que merece ser ressaltado por ter permeado, de certa forma, esse processo é o envolvimento de alunos na organização do evento. Autores como Nascimento (1994), Ferreira (2000) e Sadi (2013), recomendam que alunos possam participar da organização de atividades, envolvendo-se de modo ativo, desde o início, e não deixando a tarefa de tomada de decisões direcionada unicamente aos professores. Essa integração contribui na preparação para a vida democrática e, também, para o desenvolvimento da autonomia das crianças e jovens. De outro modo, quando não ocorre tal envolvimento não há, consequentemente, uma difusão dos valores educativos do esporte e, portanto, acaba-se reproduzindo modelos prontos de competições, tais como os olímpicos.

\section{UMA NOVA FASE DOS JEP}

Uma nova fase dos Jogos escolares de Petrolina (JEP) pôde ser demarcada com a inauguração do Centro de Educação Física6, atual Centro Regional de Esportes e Lazer, no dia 01/09/1971. A partir de então, os JEP passaram a ser disputados neste local, mesmo que a infraestrutura estivesse ainda em fase de conclusão. Este aspecto, por sua vez, foi rememorado no depoimento do professor Otacílio, evidenciando que o Centro de Educação Física não dispunha de arquibancadas e muros quando foi inaugurado (LIMA, 2015).

Tempos mais tarde, com a conclusão da obra, erigiu-se um muro com o intuito de delimitar o espaço interno do Centro. Esta demarcação, mesmo que de modo indireto, refletiu no próprio funcionamento dos JEP, que se moldou às novas condições de infraestrutura. Desta forma, uma das primeiras

${ }^{6}$ O Centro Regional de Esportes e Lazer é um complexo esportivo do governo do estado de Pernambuco, situado na cidade de Petrolina, que oferece aulas de futsal, xadrez, judô, karatê, hidroginástica, natação e capoeira para a comunidade. 
alterações foi o início da cobrança de ingressos ao público que desejasse assistir a competição. 0 valor do ingresso, por sua vez, passou a ser utilizado para custear as despesas com a organização do evento, visto que, conforme mencionamos anteriormente, não havia auxílio financeiro efetivo do estado ou do município, para subsidiar os JEP.

Dentre as despesas que passaram a ser subsidiadas com o valor arrecado da cobrança de ingressos ao público, destacamos o pagamento da arbitragem. Assim, se antes este papel era desempenhado pelos próprios professores das escolas, que se dividiam nas funções de técnicos e árbitros, a partir desta nova fase dos JEP, a arbitragem para o evento esportivo passou a ser exercida por professores vindos da capital, Recife. No entanto, conforme narrado pelo professor Otacílio em seu depoimento, a contratação de árbitros externos tornou-se custosa com o passar do tempo, visto que, era preciso arcar com as despesas de hospedagem, alimentação, além da taxa de arbitragem, durante uma semana.

Esta situação se prolongou por mais de uma década quando, então, começaram a ser realizados cursos de formação de árbitros na região (JUCHEM, 2015). Apesar desta iniciativa, os regulamentos dos JEP continuaram sendo trazidos de Recife, pois era preciso seguir os mesmos modelos dos regulamentos das competições escolares em âmbito estadual e nacional. A lógica era a seguinte: os JEP selecionavam colégios que representariam a cidade de Petrolina nos Jogos Escolares de Pernambuco; os campeões da disputa estadual, por sua vez, representavam o estado de Pernambuco nos Jogos Escolares em âmbito nacional. Por conta disso, era preciso que todas as competições escolares do estado e do país fossem coerentes e seguissem um mesmo regulamento.

As alterações organizacionais que foram sucedendo durante os anos de existência dos JEP, contribuíram para que este evento esportivo escolar fosse se consolidando com o passar dos anos. No estudo realizado por Juchem (2015), por exemplo, menciona-se o fato de a edição de 2014 contar com disputas em 10 modalidades, a saber: atletismo, basquetebol, futebol de campo, futsal, handebol, judô, natação, tênis de mesa, voleibol e xadrez. Assim, mesmo que não tenha sido possível localizar documentos escritos que forneçam informações acerca dos esportes disputados nas primeiras edições dos JEP, se pode mencionar, apoiando-se nos depoimentos orais coletados, a ocorrência de uma expansão do evento, no que se refere às modalidades esportivas.

Neste caminho, os indícios localizados durante a realização da pesquisa, nos forneceram pistas acerca das primeiras modalidades esportivas disputadas nos JEP. Na lista, figuram o atletismo, o futebol de campo, o futsal, o handebol, o tênis de mesa e o voleibol. Desta forma, torna-se perceptível a inclusão de novos esportes ao longo das edições, o que corrobora a assertiva de expansão dos JEP, sobretudo, no que concerne a gama de esportes em disputa. Talvez, este fato se relacione ao ensino de novas práticas esportivas nas escolas, ou mesmo em razão da melhoria dos equipamentos esportivos e instalações para a realização do evento, uma vez que, conforme menciona o professor Granja em seu depoimento (2015, p. 2), na primeira edição dos JEP, "as condições materiais para as disputas de atletismo [...] não eram boas". Assim, juntamente com a expansão no número de modalidades, advieram também melhores condições estruturais à prática, o que demonstra um processo de constante adequação do referido evento esportivo.

Dentre as particularidades demonstradas durante o processo de pesquisa, destacamos que a prática do handebol foi incentivada em Petrolina, inicialmente, pelos professores Bernardino, Granja e Bispo. Todavia, na primeira edição dos JEP foi disputada apenas por equipes masculinas. Acerca desta 
questão, o professor Bernardino relata em seu depoimento que, mesmo sendo o docente encarregado pelas aulas de Educação Física no Colégio Nossa Senhora Auxiliadora e um dos responsáveis pela disseminação da modalidade na região, não obtivera permissão para ensinar o handebol às alunas da instituição. Na época (início dos anos 1970), o Colégio Nossa Senhora Auxiliadora contava apenas com alunas meninas em suas turmas e, em razão disso, as diretoras não permitiram a prática da modalidade por a considerarem muito violenta. Esta realidade, todavia, foi alterada tempos depois (TEIXEIRA, 2015).

No que concerne à modalidade de natação, destacamos que esta passou a fazer parte do rol de esportes disputados no JEP, após a construção da primeira piscina pública de Petrolina, inaugurada no Centro de Educação Física, no ano de 1971. A partir daquele momento, sob a responsabilidade do professor Bernardino, os(as) alunos(as) das escolas passaram a ter aulas e treinamentos no referido local. Posteriormente a isto, as competições de natação foram incluídas no programa dos JEP.

É possível notar que, dentre os fatores que confluíam para a inclusão de modalidades esportivas no programa dos JEP, estava à existência de condições adequadas para a sua ocorrência, antes e durante as disputas. Além disso, outro ponto tido como significativo para inserção de certa prática no evento esportivo era o número de escolas que a promoviam, bem como a quantidade de participantes. 0 contrário também era verdadeiro, ou seja, na medida em que houvesse a diminuição do número de escolas participantes em determinada modalidade, esta era excluída dos JEP. Exemplos desta variação de práticas em disputa é o ciclismo, o qual fez parte da programação mas, no tempo presente, não é mais disputado. 0 mesmo ocorreu com a Ginástica Artística, na época denominada Ginástica Olímpica.

Acerca da modalidade de Ginástica Artística é relevante mencionarmos que esta fora introduzida em algumas escolas da cidade de Petrolina, pelas professoras Jocelina e Margarida Lacoch, em 1972 (JUCHEM, 2015). A inclusão desta modalidade no programa dos JEP, todavia, se deu somente no ano seguinte à sua implantação, visto que o município não dispunha de todos os equipamentos necessários para a sua realização. Apesar disso, a prática da modalidade foi enfraquecida no município após a transferência das professoras responsáveis por sua inserção. Este fato resultou na exclusão da Ginástica Artística dos JEP7.

Nos caminhos percorridos para efetivação do presente estudo, foi possível demarcarmos outro aspecto que contribuiu para a consolidação dos JEP, no contexto no qual fora conformado. Figurando de modo comum nos depoimentos orais dos professores Bernardino, Granja e Otacílio esteve a referência a realização de cursos, que tinham por finalidade a divulgação de diferentes modalidades esportivas. Tais cursos, voltados à formação de professores, sucederam-se nas cidades de Recife $(P E)$, Juazeiro (BA) e Petrolina (PE), a partir dos primeiros anos da década de 1970. Segundo a narrativa dos professores, a mencionada iniciativa auxiliou no processo de inclusão de novas modalidades esportivas nas escolas e, consequentemente, na ampliação do programa dos JEP (GRANJA, 2015; LIMA, 2015; TEIXEIRA, 2015).

Além das mudanças ocorridas com a inclusão e exclusão de modalidades esportivas em disputa, ocorreu também alterações no que tange a faixa etária dos atletas, bem como nos critérios de organização de cada categoria. Nas primeiras edições dos JEP, conforme apontaram os professores Bernardino e Granja, a participação dos atletas se dava a partir dos 12 anos de idade e se estendia

\footnotetext{
7 Destacamos que atletas oriundos das escolas de Petrolina, participantes dos JEP integraram, posteriormente, a seleção pernambucana de Ginástica Artística, vindo a representar o estado em edições do campeonato brasileiro.
} 
até os 17 anos. Os organizadores, todavia, tinham cautela durante o cruzamento das disputas, buscando evitar que uma criança de 12 anos competisse com uma de 17 anos. Acerca deste ponto, De Rose (2011) afirma que o momento ideal para as crianças participarem de competições esportivas formais é a partir dos 12 anos, visto que, a partir dessa idade, a criança passa a ter uma compreensão madura, bem como um raciocínio suficiente para entender as nuances que envolvem a competição.

Outro fator que definia a inclusão ou não de certa categoria, em determinada modalidade, segundo as formulações contidas nas narrativas dos professores Bernardino e Granja, era se o esporte em questão possuía atletas suficientes e, portanto, fosse viável a sua disputa (GRANJA, 2015; TEIXEIRA, 2015). De modo pontual, o professor Otacílio menciona o fato de os JEP terem sido disputados em três categorias, nas suas edições iniciais, a saber: categoria infantil, juvenil e adulto (LIMA, 2015). A categoria infantil era disputada por crianças e adolescentes com idade até 15 anos; a juvenil compreendia idades entre 16 e 18 anos e, por fim, a categoria adulta, era disputada por estudantes com idades a partir dos 19 anos. O professor ainda acrescenta em seu relato que, durante a gestão do professor José Gomes como diretor do Centro de Educação Física, os JEP se desenvolvem em termos organizacionais (LIMA, 2015). Foi nessa gestão, por exemplo, que ocorreu a implantação de regulamentos e regras já utilizados em Recife, além de terem sido criadas as categorias Pré-Mirim e Mirim (JUCHEM, 2015).

Nesta direção, os regulamentos incluídos também demarcaram mudanças para a competição escolar. Dentre elas, mencionamos o fato de estes estabelecerem que o tempo de disputa dos jogos, para a categoria mirim, deveria ser reduzido (comparativamente às competições de adultos). Para as categorias infantil e juvenil, no entanto, não foram definidas alterações neste quesito. Outra modificação significativa nos regulamentos dos JEP, foi mencionada pelo professor Otacílio em seu relato, quando este aludiu a alteração que previu que todos os atletas inscritos pelas escolas para disputarem as modalidades de voleibol, handebol e futsal, deveriam atuar durante os jogos. Segundo o professor Otacílio, esta mudança gerou um avanço na formação dos atletas, visto que, até o surgimento desta regra, os professores se preocupavam em estruturar equipes com atletas titulares e outros para o banco de reservas, os quais participavam da disputa apenas em alguma eventualidade (LIMA, 2015).

De modo pontual, a partir de tais alterações os professores passaram a formar e a preparar um número maior de jogadores, pois todos, obrigatoriamente, deveriam jogar. Na visão do professor Otacílio, externada através de seu depoimento, esta nova realidade tornou o processo de escolha e treinamento das equipes menos excludente. Todavia, a mudança mencionada, conforme visto, não foi aplicada a todas as modalidades. Na disputa do futebol de campo, por exemplo, estas adaptações não foram seguidas (LIMA, 2015). Tal aspecto nos levou a conjeturar que algumas das dinâmicas adotadas para o funcionamento dos JEP, muitas vezes, não eram estendidas a todas as modalidades em disputa, talvez, este fato se explique em razão das particularidades de cada esporte disputado.

A partir do que foi exposto nas linhas até então descritas, podemos perceber diferentes interfaces do esporte no ambiente escolar. De um lado, destacamos uma medida que possibilitou/determinou a participação de todos(as) os(as) alunos(as) em certa modalidade esportiva. De outro, figurou a predominância pela busca por resultados, onde ocorria a seleção por alunos(as) que possuíssem um melhor desempenho em determinada prática. Acerca deste ponto, podemos traçar uma interlocução com o estudo de Marques (1997), o qual destaca que na fase inicial da formação esportiva, quando há a promoção de competições, os organizadores, ou mesmo os responsáveis, devem ter cautela, 
pois, nesta fase a participação deve ser priorizada. Este fato, todavia, não exclui a possibilidade de premiar as equipes com melhores desempenhos nas competições. Nas edições iniciais dos JEP, por exemplo, foram premiados os primeiros colocados em cada modalidade disputada, com troféu ${ }^{8}$ para o colégio e medalha para os atletas.

Além do reconhecimento aos atletas, com o passar dos anos também passou-se a premiar o colégio campeão geral dos JEP, os quais recebiam medalhas ao classificarem-se entre as três primeiras equipes de cada modalidade. Apesar de a iniciativa representar em uma primeira vista, um incentivo às escolas, esse fato refletiu em uma desmotivação, sobretudo entre os colégios públicos, uma vez que estes possuíam, em sua maioria, condições distintas daquelas proporcionadas pelas instituições privadas. A solução para esta questão foi dada pela coordenação estadual dos jogos escolares, que resolveu estabelecer uma divisão da disputa entre colégios públicos e particulares. Assim, após tal alteração, para definir o representante da cidade, em cada uma das modalidades, realizava-se um jogo entre o colégio público campeão e o colégio particular campeão.

Nesta direção, foi possível apreendermos que as primeiras edições dos JEP se caracterizaram pela necessidade de criação, não somente de uma estrutura física e material para a realização das competições, mas, também, pela implementação de regulamentos e regras a serem utilizadas. Desta forma, uma das normas criadas pelas direções das escolas foi a de que somente os(as) alunos(as) com bom aproveitamento escolar poderiam participar e representar suas escolas nos JEP. Este critério era, segundo depoimento dos professores Bernardino e Granja, totalmente aceito pelos(as) alunos(as) e pais (GRANJA, 2015; TEIXEIRA, 2015). Assim, o(a) aluno(a) sem um bom aproveitamento escolar não participava dos jogos, mas acompanhava como torcedor, uma vez que, durante a realização dos JEP não havia aulas nas escolas.

Acerca do período para realização dos jogos, este era estabelecido em reunião com as escolas participantes. Ademais, definia-se em função dos calendários das aulas, bem como do período de férias. Os professores entrevistados relataram em seus depoimentos que uma das dificuldades encontradas durante as primeiras edições dos JEP foi com relação aos alunos que não se lembravam de levar consigo algum documento que comprovasse sua idade (GRANJA, 2015; LIMA, 2015; TEIXEIRA, 2015). Este fato ocorria em razão de as escolas, em caráter obrigatório, possuírem até 72 horas antes do início dos JEP para realizarem as inscrições das equipes. Todavia, a responsabilidade pela apresentação dos documentos, era dos(as) alunos(as), no momento da competição.

Nos casos em que o(a) aluno(a) esquecia, a solução encontrada era prosseguir com a próxima competição agendada, permitindo a busca da documentação, uma vez que, conforme relato do professor Granja (2015, p. 1), "os jogos não podiam parar". Com o passar dos anos, além do documento comprobatório da idade, passou a ser exigida também, a comprovação de frequência dos(as) alunos(as) participantes dos JEP. A escola que inscrevesse um(a) jogador(a) com menos de $50 \%$ de frequência durante o ano letivo, perdia os pontos disputados. Além desta regra, cada aluno(a) poderia ser inscrito(a) em, no máximo, duas modalidades, sendo uma coletiva e outra individual. Diante dos pontos mencionados, notou-se a ocorrência de inúmeras mudanças e adequações na competição, tanto no que se refere a inclusão e exclusão das modalidades a serem disputadas,

\footnotetext{
${ }^{8}$ Os troféus conquistados pelas escolas nas edições iniciais dos JEP, por sua vez, revelam que não existia uma padronização entre os mesmos. Ademais, foi possível perceber que empresas privadas doavam os troféus de algumas modalidades, para os organizadores dos JEP. Esse fato demonstra a colaboração da comunidade de Petrolina, na realização do evento esportivo.
} 
quando no que tange a organização das equipes, critérios de participação e premiações. Tais alterações podem ter representado um amadurecimento dos JEP que, com o passar das edições, passou a incentivar determinados aspectos que perpassavam à disputa em si e se alocavam, também, em medidas que impulsionavam uma formação ampla dos alunos, estimulando distintos valores dentro do ambiente escolar de formação.

\section{PARTICIPAÇÃO DA COMUNIDADE NOS JEP}

Os documentos de pesquisa consultados nos levaram a identificar que a consolidação dos Jogos escolares de Petrolina (JEP), no contexto no qual se fez vigente, também se deve ao vínculo criado com a própria comunidade. Em depoimento os professores entrevistados rememoraram que, desde o início, os JEP tiveram aceitação da comunidade de Petrolina (PE) e, até mesmo, do município vizinho de Juazeiro (BA) (GRANJA, 2015; LIMA, 2015; TEIXEIRA, 2015). Este fato se explica em razão de muitas crianças estudarem na cidade de Petrolina, mesmo residindo em Juazeiro. Assim, era comum que muitas famílias, tanto as residentes em Petrolina, quanto aquelas de Juazeiro e demais cidades vizinhas, assistissem aos JEP. O mesmo ocorria com as comunidades escolares, visto que durante a realização do evento esportivo, as direções, coordenações e professores(as) das escolas, auxiliavam de forma efetiva, os professores de Educação Física, na organização da competição. No entanto, na opinião do professor Otacílio, essa união já não é mais percebida no tempo presente (LIMA, 2015).

Para Reverdito e Scaglia (2013), a falta de participação da comunidade escolar (incluindo-se, portanto, escola, família e comunidade), durante a organização e realização de jogos esportivos, bem como a não inclusão destas competições no projeto político-pedagógico da escola, pode contribuir para que tais eventos se tornem cópias de competições adultas. De outra forma, os autores (2013) destacam que quando há a união da comunidade escolar na organização de um evento esportivo, oportunizase um aprendizado significativo, sobretudo para a educação e formação dos estudantes. Ao rememorar o tempo em que se envolveu na organização e que participou ativamente dos JEP, o professor Otacílio mencionou em seu depoimento o fato de as diretoras, naquela época, auxiliarem na organização, além de atuarem, também, na torcida por suas escolas. Recordou-se que não foram poucas as vezes que elas se exaltavam com a arbitragem, por exemplo. Além disso, o professor relatou aspectos sobre as músicas das torcidas, as quais eram ensaiadas nas salas de aula para serem cantadas durante os jogos, [...] "então, mesmo aquelas pessoas que não eram atletas, elas hoje, se lembram dos JEP como a "coisa mais linda", porque elas não jogavam, mas vinham rir, cantar, dançar $[\ldots]^{\prime \prime}($ LIMA, 2015, p. 4).

Dentre as lembranças que figuraram de modo comum na fala dos professores entrevistados, está a cerimônia de abertura dos JEP. Nas primeiras edições, relataram que ela ocorria no Estádio Municipal de Petrolina e, posteriormente, no Centro de Educação Física. Segundo o que consta nas memórias dos professores, a participação da comunidade era massiva, especialmente em razão do desfile em carro aberto, que contava com a participação do prefeito da cidade de Petrolina e da rainha dos JEP (GRANJA, 2015; LIMA, 2015; TEIXEIRA, 2015). Este desfile, normalmente, tinha início no centro do município, se estendia até o Estádio e, posteriormente, até o Centro de Educação Física, sendo conduzido pelo colégio mais antigo da cidade e, encerrado, com o mais novo (JUCHEM, 2015). Cabe ressaltar que eram os próprios estudantes que conduziam as bandeiras durante a abertura, vestindo trajes de gala. O professor Bernardino, recordou-se da dedicação das diretoras, evidenciando o 
quanto elas se esmeravam para que suas escolas fossem as mais organizadas na cerimônia de abertura (TEIXEIRA, 2015).

É válido ser mencionado ainda, que cada escola participava do desfile com seus respectivos atletas e, também, com suas bandas marciais. Estas, por sua vez, eram responsáveis, juntamente com a banda da Polícia Militar, pela parte musical da cerimônia de abertura. Ademais, ressaltamos que toda a cerimônia era transmitida pelas rádios da cidade, as quais narravam a ordem do desfile, além de emitirem comentários acerca dos acontecimentos e atividades em curso. Além das rádios, o extinto jornal "O Farol" também realizava a cobertura dos JEP, noticiando a programação das disputas.

Diante do exposto, é possível percebermos que, para além da atuação dos(as) professores(as), alunos(as) e direção das escolas na organização dos JEP, também tornou-se notório certo envolvimento da comunidade em geral, bem como dos meios de comunicação da cidade. Portanto, para os professores pioneiros, conforme narrado em seus depoimentos, o evento, desde o seu início, teve além da aceitação, grande reconhecimento por parte comunidade.

\section{CONSIDERAÇÕES FINAIS}

O presente estudo buscou investigar como sucederam as primeiras edições dos JEP, no princípio da década de 1970. Por meio da análise às informações de pesquisa, evidenciamos que a criação do referido evento esteve atrelada ao DERE, órgão da Secretaria de Educação de Pernambuco e, mais especificamente, a atuação dos professores José Lima Granja, Bernardino Pires Teixeira e José Pereira Bispo. Tais dados demonstram ainda, que os JEP tiveram início nos primeiros anos da década de 1970.

Recordemos que, durante este contexto (década de 1970), o país estava sob uma ditadura militar (1964-1985), conjuntura esta que instituiu medidas a todos os campos da sociedade brasileira, inclusive, no esportivo. Autores como Taborda de Oliveira (2012), demarcam que este regime utilizouse de questões intrínsecas ao esporte, tais como a conquista de títulos, obtenção de recordes e superação das dificuldades, para aproximar os ideais políticos em vigência, da população de modo geral. Lembremos também, que foi durante a segunda metade do século $X X$, que o esporte se consolidou enquanto fenômeno de massa (TABORDA DE OLIVEIRA, 2012). De outro modo, para Castellani Filho (1991), a utilização da Educação Física, pela conjuntura militar em vigência, foi interpretada como uma forma de desviar a atenção da população, do ambiente em que o país vivia. Para o autor (1991), o estado utilizava-se do esporte enquanto formador de valores de respeito às regras, para desencorajar as pessoas, a realizarem protestos ou lutarem por democracia.

De modo complementar às considerações de Castellani Filho (1991), Darido e Sanches Neto (2005) mencionam que o esporte e a Educação Física, passaram a ser utilizados pelo estado com o intuito de sustentar, ideologicamente, seu regime político. Para tanto, apropriavam-se da ideia do esporte espetáculo, utilizando-o para fomentar o crescimento e aceitação dos pensamentos políticos em voga (GHIRALDELLI JUNIOR, 2004). Para Ghiraldelli Junior (2004), tais práticas objetivavam controlar a população através dos esportes, valorizando os heróis esportivos e desenvolvendo o esporte de alto rendimento. Uma evidência desse incentivo era a oferta de bolsas de estudos, àqueles que obtivessem resultados positivos. Todavia, intrínseco a esta valorização estava à ideia de que a pessoa que se dedicasse ao esporte não haveria tempo para se envolver com a política. 
Os elementos mencionados fizeram-se presentes de certa forma, no evento esportivo de Petrolina. Na cerimônia de abertura dos JEP, por exemplo, destacou-se a presença de autoridades, além da realização de desfile das escolas participantes e eleição da rainha dos jogos. Além disso, a existência de uma tocha olímpica e do ritual de juramento dos atletas nos remetem a elementos que representam uma ideia de valorização dos "heróis esportivos" e da descoberta e promoção de talentos no esporte.

No que concerne à Educação Física, ressaltamos como reflexo do movimento advindo com a ditadura militar, a inserção e o estímulo da prática esportiva nas aulas desta disciplina, além da realização de competições escolares. Portanto, podemos pensar que o curso de capacitação oferecido aos professores de Educação Física de Petrolina e a incumbência dada a eles, para criar os JEP, conformaram-se enquanto política oficial de estado. Cabe ressaltar ainda, que até 1967 existiam no país apenas nove cursos de formação superior em Educação Física, sendo que, nem todos, estavam ligados a universidades. Estes cursos, por sua vez, capacitavam profissionais para atuação em escolas, bem como ao trabalho como treinadores esportivos (TABORDA DE OLIVEIRA, 2004).

Destarte, os JEP assumiram lugar de destaque na presente investigação, sobretudo, em razão de serem organizados de forma ininterrupta, desde a sua criação, mesmo que as condições políticosociais e as concepções educacionais tenham diferido ao longo dos anos. Portanto, as novas tendências surgidas na Educação Física brasileira fazem desta competição um evento significativo, gerando um questionamento: Quais as características e particularidades dos JEP podem ter contribuído para a sua perenidade?

A partir dos depoimentos orais dos professores que participaram da criação dos JEP, entendemos que questões como a interação e colaboração de professores(as), alunos(as) e direções das escolas, podem ter contribuído para a longevidade do evento. Apesar de ser um evento originado de uma iniciativa oficial, a participação e a colaboração de todos os personagens da escola, na superação das dificuldades, tais como a falta de locais de disputa, a carência de recursos humanos e materiais, podem o ter transformado em um evento da cultura escolar da região. Por este motivo, os JEP passam a ser um evento que os diferentes governos municipais de Petrolina têm promovido, independentemente, das políticas públicas ligadas ao esporte que são implementadas. Por fim, ressaltamos que, apesar de os JEP seguirem o modelo de esporte de alto rendimento, tornou-se notório, por meio deste estudo, que a organização do evento fez mudanças na competição ao longo dos anos, o que demonstrou, dentre outros fatores, uma preocupação com a formação dos atletas, buscando oportunizar um ambiente educacional às crianças e aos jovens que dele participam.

\section{REFERÊNCIAS}

BEGOSSI, Tuany Defaveri. A construção dos Saberes Disciplinares do Curso Normal da Escola Superior de Educação Física do estado do Rio Grande do Sul. Porto Alegre: UFRGS, 2017. Dissertação (Mestrado) - Escola de Educação Física, Fisioterapia e Dança, Universidade Federal do Rio Grande do Sul, 2017.

BRASIL. Secretaria de Educação Fundamental. Parâmetros curriculares nacionais: terceiro e quarto ciclos: educação física / Secretaria de Educação Fundamental. Brasília: MEC / SEF, 1998.

BURKE, Peter. O que é História Cultural? Rio de Janeiro: Zahar, 2008. 
CASTELLANI FILHO, Lino. Educação Física no Brasil: história que não se conta. 3. ed. Campinas: Papirus, 1991.

CHARTIER, Roger. A história hoje: dúvidas, desafios, propostas. Revista Estudos Históricos, Rio de Janeiro, vol. 7, n.13, p. 97-113, 1994.

CHARTIER, Roger. A história ou a leitura do tempo. Belo Horizonte: Autêntica Editora, 2009.

DARIDO, Suraya Cristina; SANCHES NETO, Luiz. O contexto da educação física na escola. In: DARIDO, Suraya Cristina; RANGEL, Irene Conceição Andrade (Org.). Educação física na escola: implicações para a prática pedagógica. Rio de Janeiro: Guanabara Koogan, 2005.

DE ROSE, JR. Dante. A criança o jovem e a competição esportiva: Considerações Gerais. In: DE ROSE JÚNIOR, Dante (Org.). Esporte e atividade física na infância e na adolescência: uma abordagem multidisciplinar. Porto Alegre: Artmed, 2011.

FERREIRA, Marcos Santos. Ponto de vista. A competição na educação física escolar. Motriz, Rio Claro, v.6, n. 2, p. 97-100, jul./dez., 2000.

FLICK, Uwe. Qualidade na pesquisa qualitativa. Porto Alegre: Artmed, 2009.

GHIRALDELLI JUNIOR, Paulo. Educação física progressista: a pedagogia crítico-social dos conteúdos e a educação física brasileira. 9. ed. São Paulo: Loyola, 2004.

GIBBS, Graham. Análise de dados qualitativos. Porto Alegre: Artmed, 2009.

GOLDENBERG, Mirian. A arte de pesquisar. 14ª Ed. Rio de Janeiro: Record, 2015.

GRANJA, José Lima. Petrolina: Entrevista para a tese de doutorado intitulada "Contribuições das competições esportivas para a formação e educação de crianças e jovens: o caso dos jogos escolares de Petrolina". 2015.

JUCHEM, Luciano. Contribuições das competições esportivas para a formação e educação de crianças e jovens: o caso dos jogos escolares de Petrolina. Porto Alegre: UFRGS, 2015. Tese (Doutorado) - Escola de Educação Física, Fisioterapia e Dança, Universidade Federal do Rio Grande do Sul, 2015.

LIMA, Otacílio de Souza. Petrolina: Entrevista para a tese de doutorado intitulada "Contribuições das competições esportivas para a formação e educação de crianças e jovens: o caso dos jogos escolares de Petrolina". 2015.

LYRA, Vanessa Bellani. A criação da Escola Superior de Educação Física do Rio Grande do Sul: formação de professoras(es) para a construção do campo (1940-1970). Porto Alegre: UFRGS, 2013. Tese (Doutorado) - Escola de Educação Física, Fisioterapia e Dança, Universidade Federal do Rio Grande do Sul, 2013.

LYRA, Vanessa Bellani; MAZO, Janice Zarpellon. "Os modernos methodos de ensino": a criação dos cursos intensivos de Educação Physica na capital sul-rio-grandense. Do Corpo: Ciências e Artes, Caxias do Sul, v.1, n.1, p. 1-13, jul/dez. 2011.

MARQUES, António. A preparação desportiva de crianças e jovens: o sistema de competições. In: GUEDES, Onacir Carneiro. Atividade Física: Uma abordagem multidimensional. João Pessoa: Idéia, 1997, p. 157-169. 
NASCIMENTO, Marcos Avellar. Olimpíadas escolares: em busca de uma reorientação paradigmática para sua praxis. Sprint, Rio de Janeiro v.13, n.75, p.48-50, nov./dez., 1994.

PESAVENTO, Sandra Jatahy. História \& História Cultural. 2a Ed. Belo Horizonte: Autêntica, 2004.

PICOLLI, João Carlos Jaccottet. Educação Física na escola pública do Rio Grande do Sul: antecedentes históricos (1857-1984). Pelotas: Editora da UFPEL, 1994.

REVERDITO, Riller Silva; SCAGLIA, Alcides Jose. Competições Escolares: reflexão e ação fazendo diferença nas escolas. In: REVERDITO, Riller Silva; SCAGLIA, Alcides Jose; MONTAGNER, Paulo Cesar (Org.). Pedagogia do esporte: aspectos conceituais da competição e estudos aplicados. São Paulo: Phorte, 2013.

REVERDITO, Riller Silva; SCAGLIA, Alcides José; SILVA, Sidney Aparecido Dias da; GOMES, Thales Marcel Ribeiro; PESUTO, Claudinei de Lima; BACCARELLI Walter. Competições Escolares: reflexão e ação em Pedagogia do Esporte para fazer a diferença na escola. Revista Motriz, n. 11, v. 1, p. 3745A jan./jul. 2008.

SADI, Renato Sampaio. A complexidade da competição esportiva diante do paradigma do ambiente social competitivo e das possibilidades pedagógicas que os professores de Educação Física dispõem. 2013.2 Disponível em: <https://www.researchgate.net/profile/Renato_Sadi/publication/278965795>. Acesso em: 26/06/2018.

TABORDA DE OLIVEIRA, Marcos Aurelio. Esporte e política na ditadura militar brasileira: a criação de um pertencimento nacional esportivo. Movimento, Porto Alegre, v. 18, n. 4, p.155-174, out./dez., 2012.

TABORDA DE OLIVEIRA, Marcos Aurelio. O esporte como conteúdo privilegiado das aulas de Educação Física nos anos da ditadura militar (1971-1984): o que têm a nos dizer os professores escolares? In: Anais do III Congresso Brasileiro de História da Educação. 2004. Disponível em: <http://www.sbhe.org.br/novo/congressos/cbhe3/Documentos/Coord/Eixo4/470.pdf>. Acesso em: 26/06/2018.

TEIXEIRA, Bernardino Pires. Petrolina: Entrevista para a tese de doutorado intitulada "Contribuições das competições esportivas para a formação e educação de crianças e jovens: o caso dos jogos escolares de Petrolina". 2015.

Submissão: 26/06/2018

Aceito: $27 / 08 / 2018$ 